\title{
Spectroscopic Characteristics of Treated-Color Natural Diamonds
}

\author{
Meili Wang, ${ }^{1}$ Guanghai Shi $\mathbb{D}^{1}{ }^{1}$ Joe C. C. Yuan, ${ }^{2}$ Wen Han, ${ }^{3}$ and Qing Bai ${ }^{1}$ \\ ${ }^{1}$ State Key Laboratory of Geological Processes and Mineral Resources, China University of Geosciences, Beijing, China \\ ${ }^{2}$ Taidiam Technology (Zhengzhou) Co. Ltd., Zhengzhou, China \\ ${ }^{3}$ National Gems \& Jewelry Technology Administrative Center, Beijing, China
}

Correspondence should be addressed to Guanghai Shi; shigh@cugb.edu.cn

Received 15 October 2017; Accepted 28 December 2017; Published 7 March 2018

Academic Editor: Vincenza Crupi

Copyright (c) 2018 Meili Wang et al. This is an open access article distributed under the Creative Commons Attribution License, which permits unrestricted use, distribution, and reproduction in any medium, provided the original work is properly cited.

\begin{abstract}
With the increasing availability of treated-color diamonds on the market, their characterization is becoming more and more critical to the jewelry testers and customers. In this investigation, ten color diamonds treated by irradiation (4 pieces), HPHT ( 3 pieces), and multiprocess ( 3 pieces) were examined by spectroscopic methods. These diamonds are classified to be type Ia according to their FTIR characteristics. Using microscope and DiamondView, the internal features (such as distinctive color zoning and graphitized inclusions) and complex natural growth structures were observed, which show that the samples are more likely artificially colored natural diamonds. Through photoluminescence spectroscopy, a combination of optical centers was detected, including $\mathrm{N}-\mathrm{V}^{0}$ at $575 \mathrm{~nm}, \mathrm{~N}-\mathrm{V}^{-}$at $637 \mathrm{~nm}, \mathrm{H} 3$ at $503 \mathrm{~nm}, \mathrm{H} 2$ at $986 \mathrm{~nm}$, and GR1 at 741 and $744 \mathrm{~nm}$. Combining with the previous studies, treatment conditions for the studied diamonds were estimated depending on the presence and/or absence of the optical centers. In addition, the coloration mechanism of the samples (blue, green, and red) during the treatment process was also discussed. It is suggested that a number of techniques should be combined in order to make a reliable identification for such diamonds.
\end{abstract}

\section{Introduction}

Diamonds, one of the most precious gemstones, have been very popular on the jewelry market, especially the fancy color gem-quality diamonds. However, most natural diamonds show brown hue in color and have some internal or external defects, and only a few of them are suitable for using as gemstones [1]. Therefore, considerable scientific work has been continuously done to enhance the color of diamonds so as to make them exhibiting fancy color, in order to offset the scarcity of natural diamonds and to satisfy the demand for color gem-quality diamonds of the jewelry market.

Generally, the gemologists have begun to enhance the color of diamond since the 1930s [2] and diamond treatments in the modern era mostly involve high-energy irradiation, high pressure and high temperature (HPHT) treatment, low pressure and high temperature (LPHT) annealing, and combination of these treatments [3-11]. Such as Vins [12] reported that natural diamonds with brown hue could be altered to display purple to red color, through multiprocess treatments including HPHT treatment $(6-7 \mathrm{GPa}$ at over $2150^{\circ} \mathrm{C}$ ), high-energy irradiation, and LPHT annealing (lower than $1100^{\circ} \mathrm{C}$ ).

With the increasing availability of the treated-color diamonds in the jewelry market, characterization of them becomes more and more critical to the gem testers and customers. However, by far, there are not enough works for systematically studying the treated-color diamonds and most of them are focused on examining the diamonds treated by the same method or that from the same company [13-15]. This study attempts to characterize the natural diamonds treated by different process (irradiation, HPHT, and multiprocess) using spectroscopic methods, to present the coloration mechanism of them during treatment, and to provide more data of the identification and the treatment method for the gemologists and the jewelry market.

\section{Materials and Methods}

Ten treated-color natural diamonds were collected for this investigation (4 irradiation-treated, 3 HPHT-treated, and 3 multiprocess-treated diamonds, see Table 1 and Figure 1). 
TABLE 1: Description of the treated-color natural diamonds used in this study.

\begin{tabular}{|c|c|c|c|c|c|c|}
\hline & Sample number & Color & Weight (ct) & Clarity & $\begin{array}{l}\text { Fluorescence to } \\
\text { long-wave UV }\end{array}$ & $\begin{array}{l}\text { Fluorescence to } \\
\text { short-wave UV }\end{array}$ \\
\hline \multirow{4}{*}{ Treated-irradiated } & TR-1 & Blue & 0.4 & $\mathrm{SI}_{2}$ & Very weak blue, chalky & Invert \\
\hline & TR-2 & Dark green & 0.24 & $\mathrm{SI}_{1}$ & Moderate green, chalky & Invert \\
\hline & TR-3 & Blue & 0.24 & $\mathrm{VVS}_{2}$ & Invert & Invert \\
\hline & TR-4 & Dark green & 0.36 & $\mathrm{VS}_{1}$ & Invert & Invert \\
\hline \multirow{3}{*}{ Treated-HPHT } & TR-5 & Yellowish green & 0.38 & $\mathrm{VS}_{1}$ & Greenish yellow & Moderate greenish yellow \\
\hline & TR-6 & Yellow & 0.42 & $\mathrm{SI}_{1}$ & Weak blue, chalky & Invert \\
\hline & TR-9 & Greenish yellow & 0.29 & $\mathrm{SI}_{2}$ & Blue, chalky & Greenish yellow \\
\hline \multirow{3}{*}{ Treated-multiprocess } & TR-7 & Dark purplish pink & 0.39 & $\mathrm{I}_{1}$ & Pink, chalky & Moderate orange \\
\hline & TR-10 & Dark purplish pink & 0.35 & $\mathrm{SI}_{2}$ & Weak pink, chalky & Weak orange \\
\hline & TR-11 & Slight dark red & 0.30 & $\mathrm{SI}_{1}$ & Very weak blue & Invert \\
\hline
\end{tabular}

Treated-irradiated
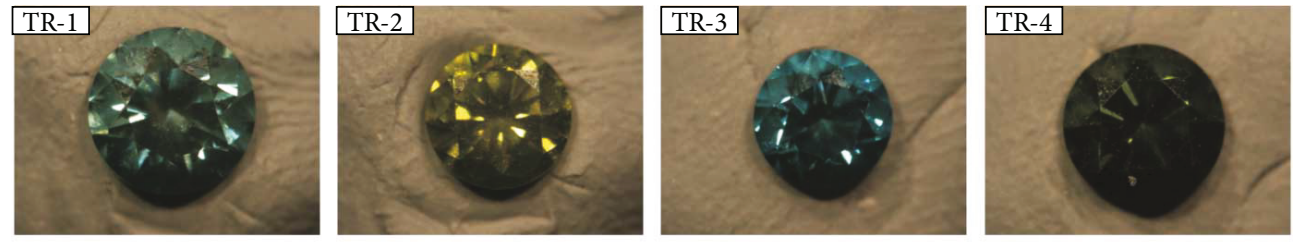

Treated-HPHT
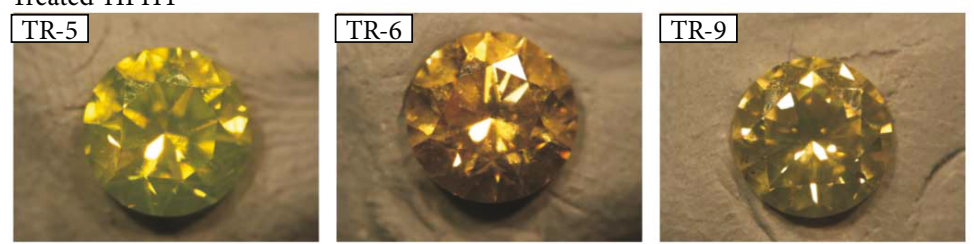

Treated-multiprocess
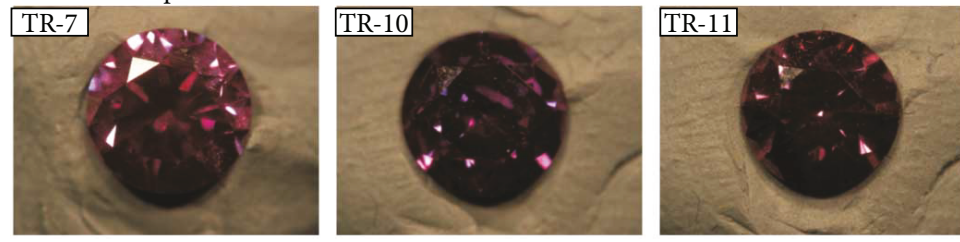

FIGURE 1: These faceted diamonds are treated by irradiation, HPHT, and multiprocess treatments, respectively, and they range in size from 0.24 to 0.42 ct.

All the faceted samples are round brilliants and range in size from 0.24 to $0.42 \mathrm{ct}$. Using a standard gemological binocular microscope, the internal features of all diamonds were examined. The reactions to ultraviolet (UV) light were checked with a conventional four-watt combination longwave $(365 \mathrm{~nm})$ and short-wave $(254 \mathrm{~nm})$ lamp (Table 1). In addition, we recorded the fluorescence and phosphorescence images by the Diamond Trading Company (DTC) DiamondView instrument (illumination wavelengths $<230 \mathrm{~nm}$, Welbourn et al. [16]) in the laboratory of National Gems \& Jewelry Technology Administrative Center (NGTC) in Beijing, and which could also reveal the internal growth features of the samples.

Two other spectroscopic analyses were conducted on most of the samples at NGTC laboratory. Infrared absorption spectra in the midinfrared $\left(4000-400 \mathrm{~cm}^{-1}, 2 \mathrm{~cm}^{-1}\right.$ resolution) were measured by a Thermo Nicolet Nexus iN10 Fouriertransform infrared (FTIR) spectrometer, furnished with $\mathrm{KBr}$ and quartz beam splitters. A total of 64 scans were collected for each sample. A Renishaw InVia Raman confocal microspectrometer was used to acquire the low temperature photoluminescence (PL) spectra, with the samples cooled by submerging in liquid nitrogen. To activate various types of defects in these treated-color natural diamonds, three different excitation wavelengths (473, 532, and $785 \mathrm{~nm}$ ) were employed.

\section{Results}

3.1. Microscopic Characteristics. Viewing with the binocular gemological microscope, natural mineral inclusion and internal growth graining were observed in some of the treated- 
color diamonds, which indicated that they had grown naturally, as shown in Figures 2(a) and 2(b). Some of them display color zoning, as the most characteristic feature of the treated diamonds (Figure 2(c)). In addition, other evidences of treatment were also noted, such as one diamond exhibited etched facet near to the girdle which was not removed during polishing (Figure 2(d)) and some graphitized inclusions formed during the HPHT treatment were also shown (Figure 2(e)). Besides, under magnification with crossed polarizer, anomalous birefringence with high interference colors caused by residual internal strain was observed in all treated diamonds (Figure 2(f)).

3.2. DiamondView Imaging. When exposed to the highintensity ultrashort wavelengths of the DTC DiamondView, the treated-color diamonds exhibited strong green, blue, orange, and orangey red fluorescence (Figure 3 ). In general, one sample could display two or more different fluorescence color. For example, numerous red, orangey red, blue, and slight green fluorescence lines were simultaneously present in the TR-10 sample (Figure 3(h)). The TR-6 sample with blue fluorescence displayed some irregular green regions as shown in Figure 3(e). In addition, the luminescence images of the examined diamonds revealed complex growth patterns, which is a typical reflection of complex growth history and also the natural origin.

3.3. Infrared Absorption Spectroscopy. As shown in Figures 4(a) and 4(b), all the irradiation-treated diamonds are assigned to be type IaAB according to their infrared spectra. The absorption from the H1a defect (the $<001>$ dinitrogen split interstitial $\mathrm{N}_{21}$; [17]) at $1450 \mathrm{~cm}^{-1}$ is observed in all the irradiated diamonds, which points out that they have been irradiated or irradiated with subsequently annealing at relatively low temperatures $\left(\sim 300^{\circ} \mathrm{C}\right.$; Clark et al. [18]). The absence of band of $2800 \mathrm{~cm}^{-1}$ in the blue diamonds is another evidence for the existence of irradiation. Absorption peaks located at near $1356 \sim 1380 \mathrm{~cm}^{-1}$ are related to C-C platelets, which represent for the layers of interstitial carbon atoms generated as a byproduct of nitrogen aggregation [19]. In addition, the intensity of band of $1405 \mathrm{~cm}^{-1}$ is found to be positive related to that of $3107 \mathrm{~cm}^{-1}$, indicating that both of them may originate from the same $\mathrm{VN}_{3} \mathrm{H}$ defect [20]. The peak at $2785 \mathrm{~cm}^{-1}$ was reported to be produced by the vibrations of 1405 and $3107 \mathrm{~cm}^{-1}$ [21]. Besides, the double peak at $\sim 2926$ and $\sim 2854 \mathrm{~cm}^{-1}$, attributing to C-H stretch [22], is observed in all the samples. Unknown weak or sharp bands of the two dark green diamonds are also detected at 3254, 3236, 3069, 3056, 2812, 2785, 1553,1524, 1528,1499 , and $1435 \mathrm{~cm}^{-1}$, and we speculate that some of them may arise from the hydrogen in diamonds.

The FTIR spectra of the HPHT-treated samples display typical features of type Ia, with various aggregation states of nitrogen. As represented in Figures 4(c) and 4(d), the TR-6 sample shows stronger A-aggregate absorption while the other two show stronger B-aggregate features. The occurrence of $1331 \mathrm{~cm}^{-1}$, associated with the positive charge state of the single substitutional nitrogen defect $\left(\mathrm{N}^{+}{ }_{\mathrm{s}}\right.$, may indicate that the diamonds have been treated by HPHT process which can create isolated nitrogen [23]. Additionally, the two TR-5 and TR-9 samples also exhibit absorption related to hydrogen impurities at $3107 \mathrm{~cm}^{-1}$.

The multiprocess-treated diamonds are proved to be type IaAB (Figures 4(e) and 4(f)), where the concentration of $\mathrm{A}$-aggregates is stronger than that of $\mathrm{B}$-aggregates. Weak absorptions at 1344 and $1331 \mathrm{~cm}^{-1}$ attributed to isolated nitrogen impurities are recorded in all the samples. In addition, the H1a defect due to irradiation is observed in this group of samples. Other weak and broad features also occurred in some of them, including peaks at 3107, 1502, and $1405 \mathrm{~cm}^{-1}$, where the $1502 \mathrm{~cm}^{-1}$ center was suggested to be related to the H1a center according to their positive correlation in intensity [24].

3.4. Photoluminescence Spectroscopy. Low temperature photoluminescence spectra were collected for most of the samples using three laser excitations with wavelengths of 473,532 , and $785 \mathrm{~nm}$. The major PL emission lines are illustrated below based on each laser excitation.

As illustrated in Figures 5(a)-5(c), when the $473 \mathrm{~nm}$ laser excitation is employed, all the treated diamonds display the H3 $(503.2 \mathrm{~nm})$ defect, with side bands between $\sim 512$ and $\sim 553 \mathrm{~nm}$, and with various intensity between different samples. A faint emission line at $496 \mathrm{~nm}$, assigned to be $\mathrm{H} 4$ center, occurs in the irradiation-treated and multiprocesstreated diamonds. At the same time, a set of emissions at 484,486 , and $491 \mathrm{~nm}$ are present in some of the samples in these two groups; however, it is unknown whether they are related with the $\mathrm{H} 4$ defect or not. Besides, the $3 \mathrm{H}$ defect (a radiation center of diamond $[22,25]$ ) is not found in the irradiation-treated diamonds, which needs further exploration. Nitrogen-vacancy centers $\left(\mathrm{NV}^{0} /^{-}\right)$, with zero-phonon lines at 575 and $637 \mathrm{~nm}$, are obvious in the multiprocesstreated diamonds. However, they are absent in the HPHTtreated diamonds and only one of the irradiation-treated diamonds shows very weak $\mathrm{NV}^{0}$ center. In addition, one spectrum of the HPHT-treated diamonds displays an intense peak at $478.9 \mathrm{~nm}$ (not shown), which was suggested to be an indicator of possible HPHT treatment [26]. The $588 \mathrm{~nm}$ emission, considered as an evidence of multiprocess treatment [26], is observed in the multiprocess-treated diamonds. These spectra also reveal peaks at $634.4 \mathrm{~nm}$ in the HPHTtreated diamonds, at 489.1, 558.1, 613.5, 647.1, and $657.9 \mathrm{~nm}$ in the irradiation-treated diamonds, and at $600.2 \mathrm{~nm}$ in the multiprocess-treated diamonds.

The PL spectra taken with $532 \mathrm{~nm}$ laser excitation reveal sharp NV center emission systems in most of the treated samples, with the intensity of the $637 \mathrm{~nm}$ ZPL more intense than that of $575 \mathrm{~nm}$ ZPL. Another band is detected at $\sim 658 \mathrm{~nm}$ in most of the samples, which was suggested to be created at high temperatures and then destructed by HPHT treatment [27]. Strong doublet emissions at 741.4 and $744.7 \mathrm{~nm}$, attributed to GR1 center, are observed in the irradiation-treated diamonds. In addition, numerous emission lines at 536.0, 539.7, 542.9, 551.0, 558.2, 588.1, 563.6, $603.5,609.3,612.5,640.0,647.3, \sim 680, \sim 715, \sim 723, \sim 757$, $\sim 787$, and $\sim 800 \mathrm{~nm}$ are detected in the spectra of the irradiation-treated diamond. Other features are also recorded 


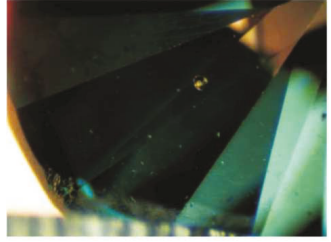

(a) TR-1

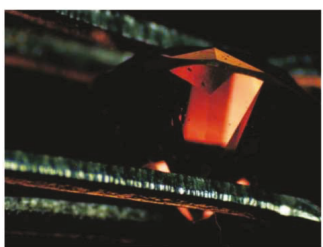

(d) TR-7

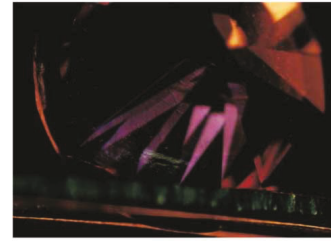

(b) TR-10

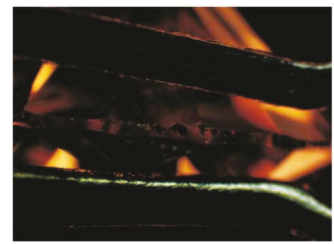

(e) TR-6

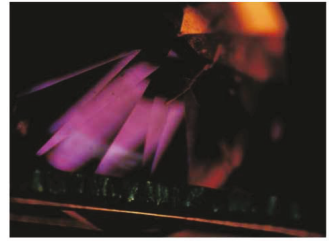

(c) TR-10

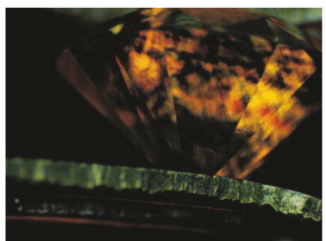

(f) TR-5

FIGURE 2: A broad range of internal characteristics were noted with magnification, including natural mineral inclusions and some graphitized inclusions, as well as color zoning and etched facet near to the girdle. In addition, anomalous birefringence with high interference colors was also observed.

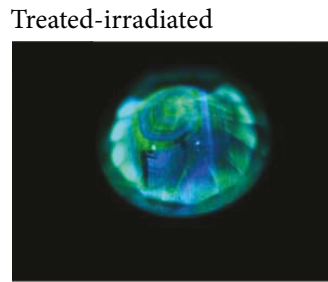

(a) TR-1

Treated-HPHT

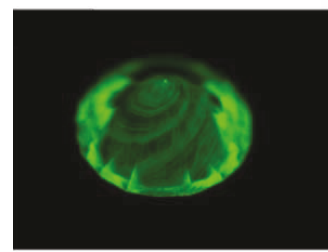

(d) TR-5

Treated-multiprocess

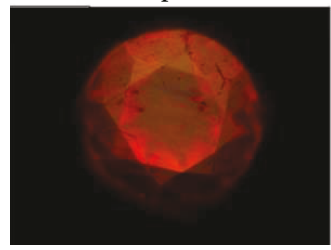

(g) TR-7

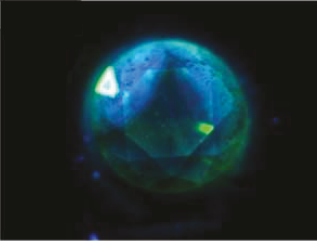

(b) TR-2

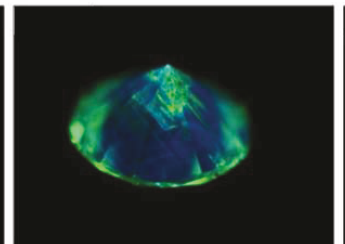

(e) TR-6

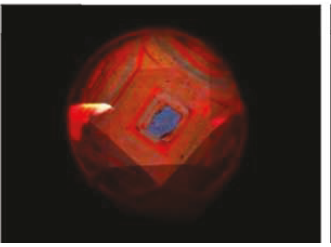

(h) TR-10

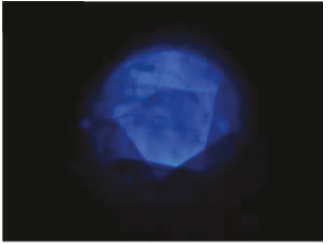

(c) TR-3

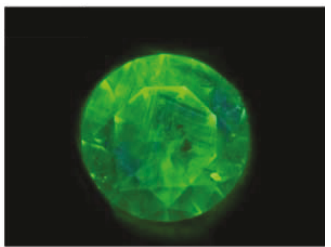

(f) TR-9

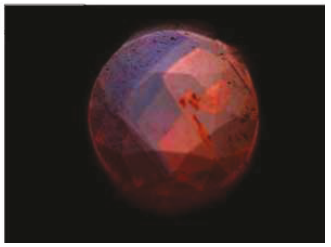

(i) TR-11

FIGURE 3: DiamondView images showed complex growth patterns of the treated-color diamonds, which revealed the natural origin. The dominant luminescence was strong green, blue, orange, and orangey red, and while one sample usually displayed two or more different fluorescence.

in the HPHT-treated diamond, including peaks at 536.1, $539.8,555.3,565.3,566.2$, and $601 \mathrm{~nm}$. The defects responsible for most of these emission lines have not been identified.

Infrared laser excitation at $785 \mathrm{~nm}$ produces two emission features $(876.4 \mathrm{~nm}$, the first order diamond Raman line, and $986.2 \mathrm{~nm}$, the H2 center) in the HPHT-treated diamonds.
We also observe another weak peak at $959.7 \mathrm{~nm}$ in one of these samples. In the irradiation-treated diamonds, many weak and sharp peaks are recorded, including those at 795.3, 799.2, $802.5,805.4,806.4,839.7,890.5,900.6,926.3,936.7,948.6$, 960.3 , and $986.4 \mathrm{~nm}$. The spectra of the multiprocess-treated diamonds reveal several features at 789.9, 805.1, 815.9, 


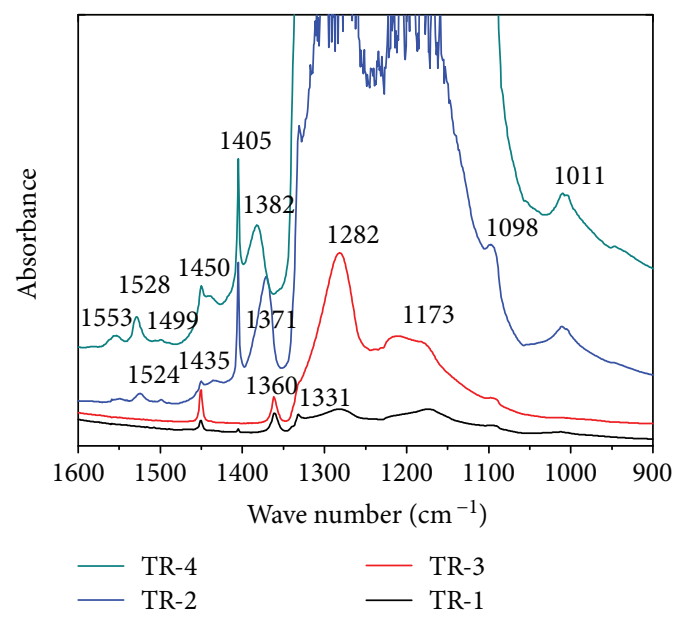

(a)

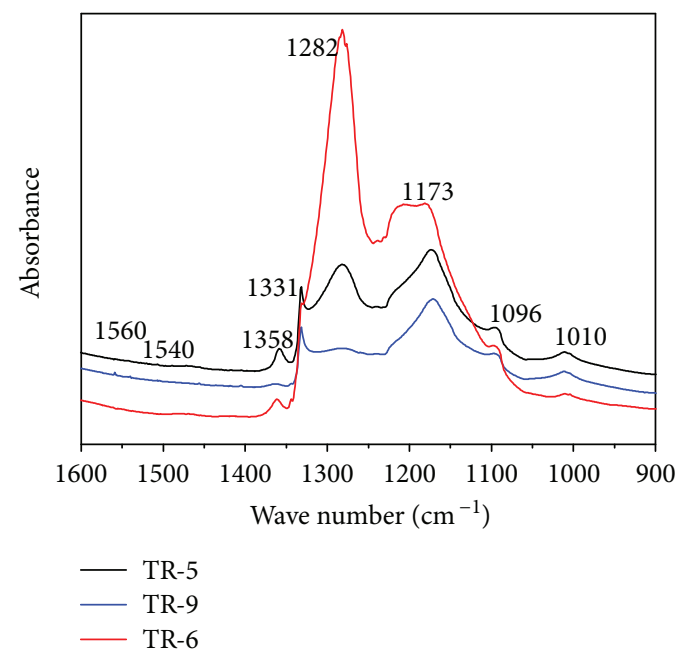

(c)

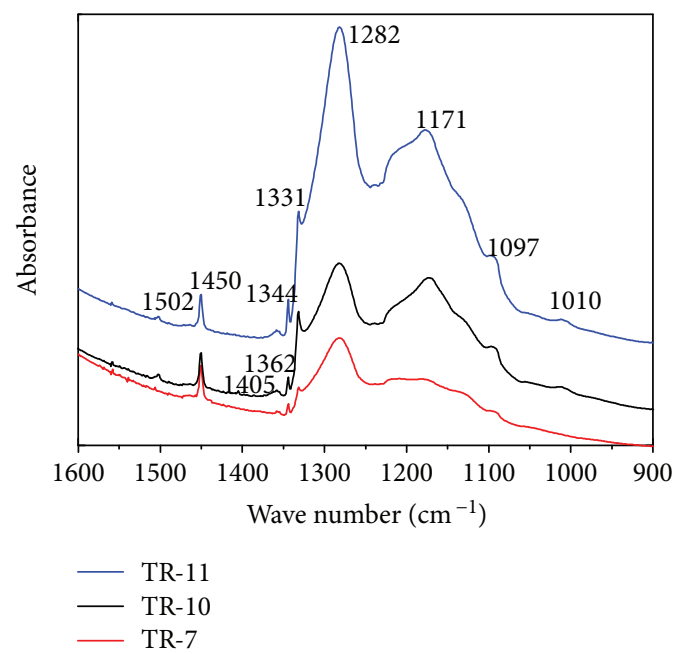

(e)

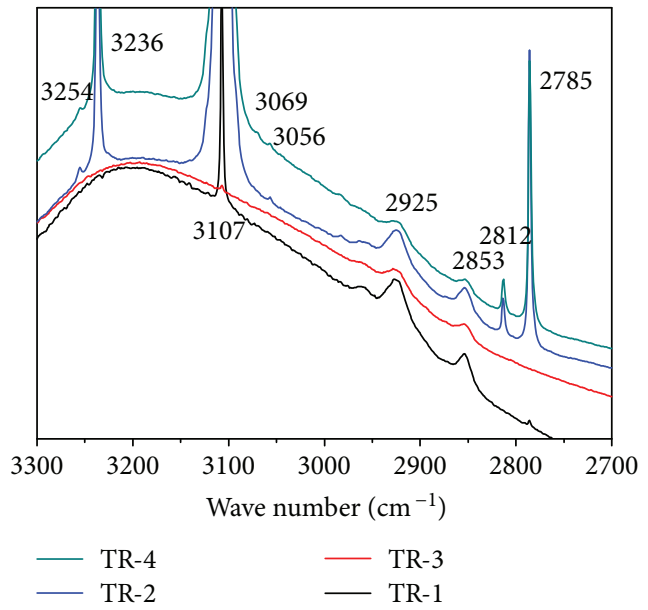

(b)

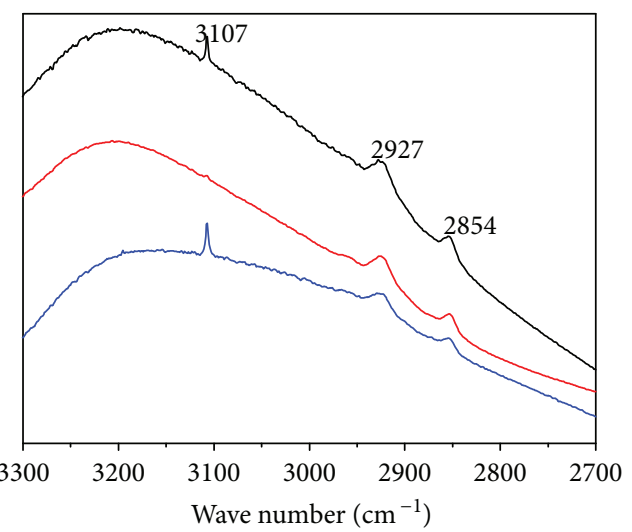

TR-5
TR-9

- TR-6

(d)

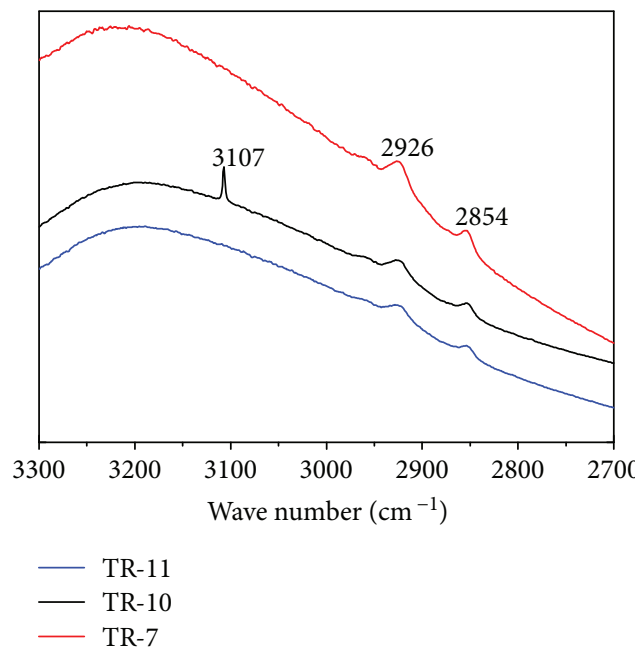

(f)

FIGURE 4: The FTIR spectra of the treated-color diamond collected in the midinfrared range reveal typical features of type Ia diamonds, with various aggregation states of nitrogen. The $\mathrm{H} 1 \mathrm{a}$ absorption at $1450 \mathrm{~cm}^{-1}$ and the isolated nitrogen-related peaks $\left(1344\right.$ and $1331 \mathrm{~cm}^{-1}$ ) were also observed in some of them. 

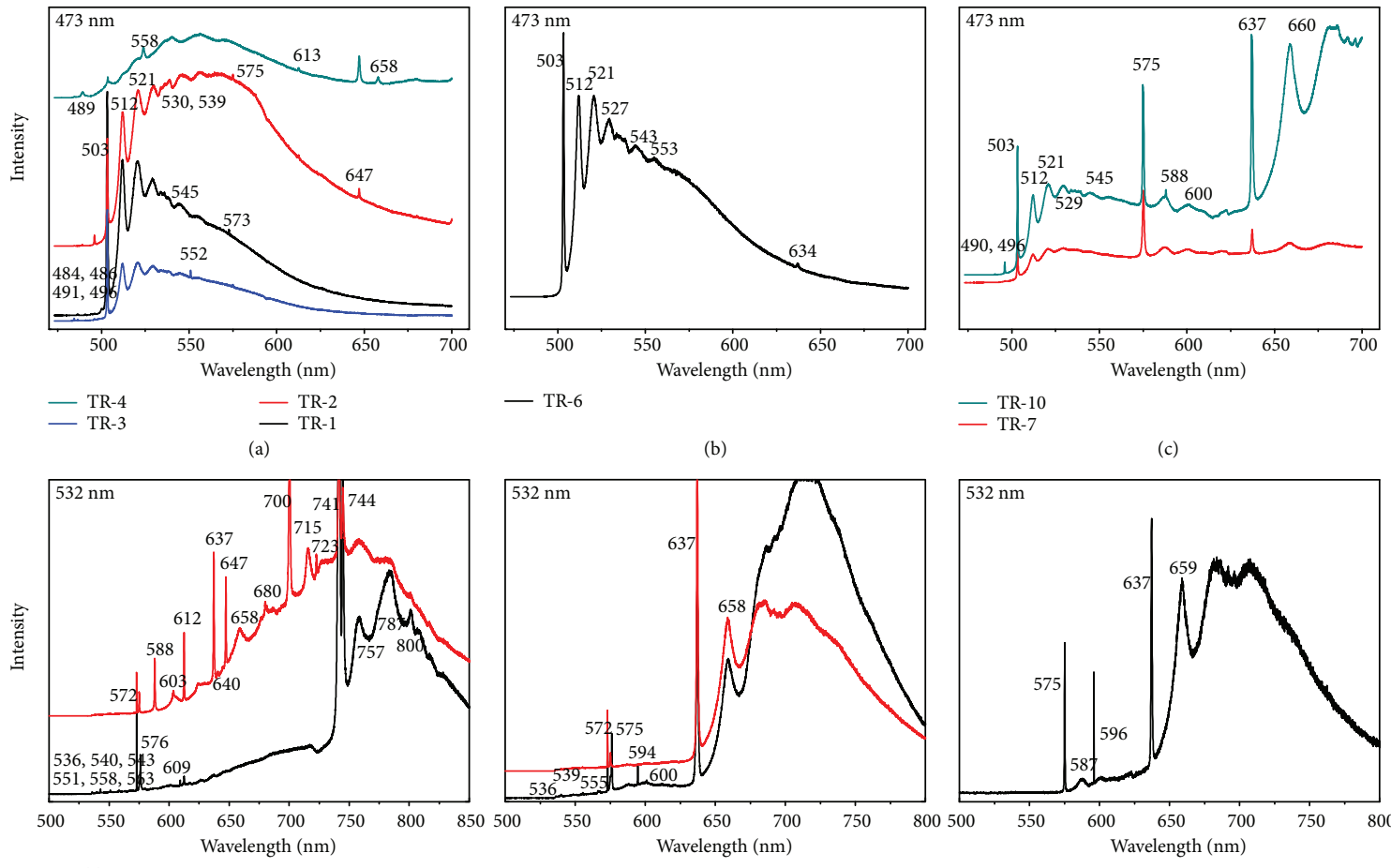

(b)

二 ${ }^{\mathrm{TR}-10}$

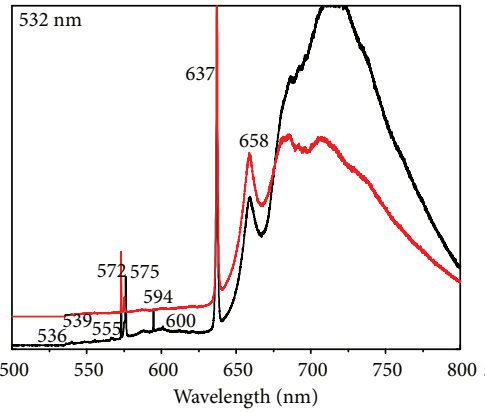

$$
\text { — TR-2 }
$$

二 ${ }^{\mathrm{TR}-6}$

(e)

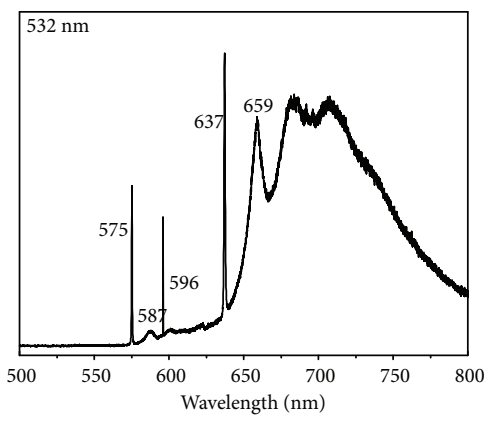

(d)
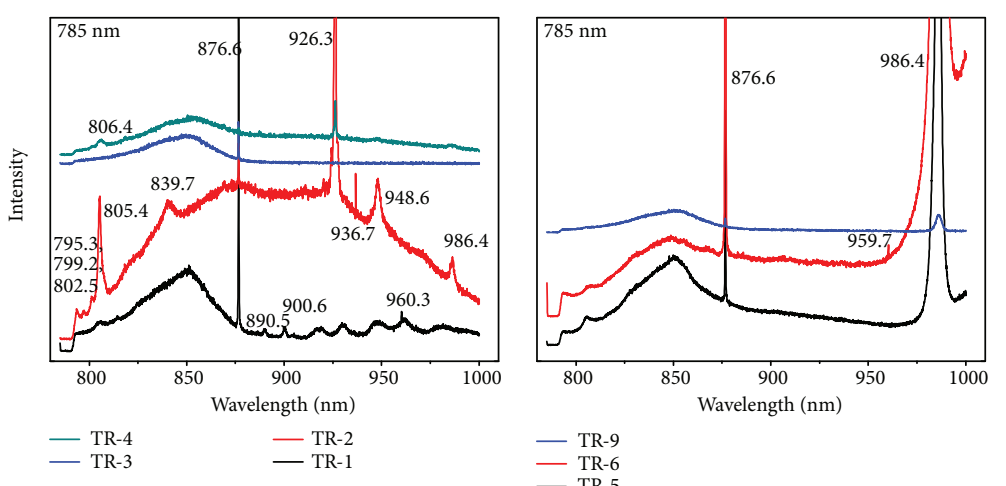

- TR-7

(f)

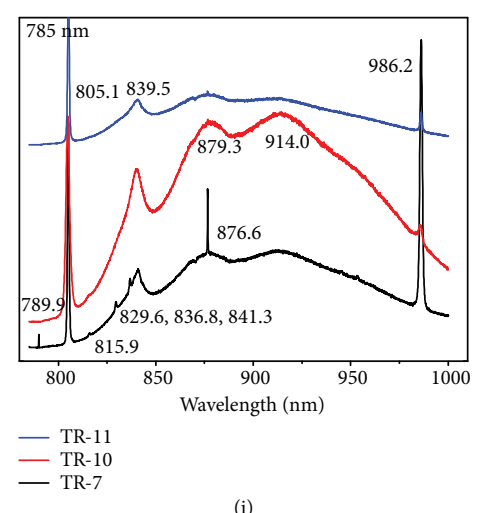

(g)

\begin{tabular}{c} 
TR-9 \\
T ${ }^{\text {RR-6 }}$ \\
\hline TR-5
\end{tabular}

(i)

Figure 5: Photoluminescence spectra were taken at liquid-nitrogen temperatures for most of the samples using three laser excitation wavelengths of 473, 532, and $785 \mathrm{~nm}$. Strong H3 center, NV center, GR1 center, and H2 center were observed in some of these treatedcolor diamonds. The presence and/or absence of these centers have an indicative role to determine the type of treatment and the process of the treatment.

$829.6,836.8,839.5,841.3$, and $986.2 \mathrm{~nm}$. Unfortunately, the assignments for most of them are not sure.

\section{Discussions}

4.1. Spectroscopic Features and Related Treatment. Usually, the condition of treatment correlates with the presence and/ or absence of the optical centers, and thus analysis of the optical centers may contribute to reveal the condition of treatment. The variations of some optical centers with different treatment processes and conditions in previous works are reviewed as followed.

4.1.1. $\mathrm{H} 3$ and $\mathrm{H} 2$ Centers. The $\mathrm{H} 3(503.2 \mathrm{~nm})$ and $\mathrm{H} 2$ $(986.2 \mathrm{~nm})$ centers are related to the nitrogen-vacancy- nitrogen (NVN) defect in neutral and negative charge state, respectively. Commonly, the $\mathrm{H} 3$ center has been observed in diamonds involving with irradiation and high temperature annealing (or HPHT annealing) [28-30] or been directly created in plastically deformed brown diamonds through heating at high temperature $[31,32]$, while various concentrations of the $\mathrm{H} 3$ defect can also occur in some natural diamonds [33-36]. In nitrogen-containing diamonds, highenergy irradiation followed by annealing at temperatures over $500^{\circ} \mathrm{C}$ could result in the formation of $\mathrm{H} 3$ center [26]. Collins [37] reported that the $\mathrm{H} 3$ center had maximum intensity at approximately $800^{\circ} \mathrm{C}$ and annealed out at temperatures above $1500^{\circ} \mathrm{C}$ in irradiated diamonds. In terms of the HPHT annealing treatment for the irradiated type Ia diamonds, the $\mathrm{H} 3$ absorption just began to decrease after $1650^{\circ} \mathrm{C}$ 
[28] or reduced largely or disappeared after high pressure annealing at $2300^{\circ} \mathrm{C}$ [29]. While in most of the HPHTtreated diamonds, the $\mathrm{H} 3$ center may form in brown plastically deformed type IaA and $\mathrm{IaB}$ diamonds when annealed at a temperature $1800^{\circ} \mathrm{C}$ at $7.0 \mathrm{GPa}$ and then its concentration increased up to about $2150^{\circ} \mathrm{C}[32,38]$ or decreased considerably at temperatures above $2100^{\circ} \mathrm{C}[39,40]$.

The $\mathrm{H} 2$ center, with negative charged state, is usually observed in diamonds containing defects which can act as donors. In irradiated type IaA diamonds, the absorption of the $\mathrm{H} 2$ center started to increase after annealing at around $1250^{\circ} \mathrm{C}$ and reached a maximum at $1600^{\circ} \mathrm{C}$ or disappeared when annealed at $2300^{\circ} \mathrm{C}$ and high pressure $[28,29]$. Through HPHT annealing with temperatures above 1800/ $1900^{\circ} \mathrm{C}$, in type IaA/IaB diamond with plastic deformation, the absorption of the $\mathrm{H} 2$ center appeared and increased with increasing temperature and then began to decrease at 2150/ $2200^{\circ} \mathrm{C}[38,39]$.

4.1.2. GR1 Center. The GR1 center is attributed to the neutral isolated vacancy $\left(\mathrm{V}^{\circ}\right)$, located at 741 and $744 \mathrm{~nm}$. Weak line at $741 \mathrm{~nm}$ has been found in a few natural diamonds [41, 42]. Through high-energy irradiation (electrons, gamma-rays, neutrons, and ions), the GR1 center could be artificially created in most of diamonds [22, 26]. Kiflawi et al. [43] reported that there was an initial reduction in the strength of the GR1 absorption at $390-410^{\circ} \mathrm{C}$ followed by sharp decrease beyond $700^{\circ} \mathrm{C}$ in the irradiated diamonds. In addition, the GR1 center is completely destroyed in high-nitrogen diamonds when heated at $800^{\circ} \mathrm{C}$ for $1 \mathrm{~h}$, whereas heating above $900^{\circ} \mathrm{C}$ was required in low-nitrogen specimens $[28,44]$. The GR1 center was absent in irradiated diamonds upon HTHT treatment at $1000^{\circ} \mathrm{C}[26]$.

4.1.3. NV Center. One of the nitrogen-vacancy defects locates at $575 \mathrm{~nm}$ in neutral charge state $\left(\mathrm{NV}^{0}\right)$, and the other one locates at $637 \mathrm{~nm}$ in negative charge state $\left(\mathrm{NV}^{-}\right)$. In irradiated diamonds, the $575 \mathrm{~nm}$ center annealed out at approximately $1400^{\circ} \mathrm{C}$; however, in some cases, it was still stable at temperatures above $1600^{\circ} \mathrm{C}$ and it could survive to about $2000^{\circ} \mathrm{C}$ when the diamonds were heated under high pressure $[22,25]$. Vins and Eliseev [38] suggested that the A defects began to dissociate and some $\mathrm{C}$ defects (isolated nitrogen impurities) were formed in brown type IaA diamond after HPHT annealing at $2100^{\circ} \mathrm{C}$, and a weak absorption of the NV defects simultaneously appeared.

The $637 \mathrm{~nm}$ center in electron irradiation type Ia diamonds began to develop after annealing at $800^{\circ} \mathrm{C}$ [5] and may anneal out at about $1500^{\circ} \mathrm{C}$ [25]. In addition, when the irradiated type Ia diamonds are subjected to $2300^{\circ} \mathrm{C}$ at $5.0 \mathrm{GPa}$, the $637 \mathrm{~nm}$ absorption is extremely weak or undetectable [29]. In type Ia brown diamonds, the $\mathrm{NV}^{-}$center was produced by HPHT treatment at $2000^{\circ} \mathrm{C}$ and above $[4,34]$ and could be rather strong through a few minutes of HPHT treatment at a temperature of $2300^{\circ} \mathrm{C}$ [45].

4.1.4. Other Features. The $3107 \mathrm{~cm}^{-1}$ center is attributed to $\mathrm{H}$-related vibration and is assigned to be mode of $\mathrm{VN}_{3} \mathrm{H}$ $[20,46]$. In general, the behavior of the $3107 \mathrm{~cm}^{-1}$ during treatment is complex. After electron irradiation and subsequent prolonged annealing at $1200^{\circ} \mathrm{C}$ for $24 \mathrm{~h}$, the intensity of the $3107 \mathrm{~cm}^{-1}$ absorption in type Ia diamonds can be considerably reduced or even disappeared [47]. The study of De Weerdt and Kupriyanov [48] showed that the $3107 \mathrm{~cm}^{-1}$ absorption was stable in type IaA/B diamonds when annealing at $1900^{\circ} \mathrm{C}$ and $7.0 \mathrm{GPa}$. As summarized by Dobrinets et al. [26] and Vins and Yelisseyev [39], HPHT treatment could strongly reduce the intensity of the $3107 \mathrm{~cm}^{-1}$ in $80 \%$ of cases. The $\mathrm{C}$ center is related to the isolated nitrogen, located at 1344 and $1131 \mathrm{~cm}^{-1}$. Usually, the presence of $C$ center in the FTIR spectrum of type IaAB is an indication of possible HPHT treatment. After HPHT treatment performed at $2000^{\circ} \mathrm{C}$ and above, the $\mathrm{C}$ defects with detectable concentration appeared [38, 45, 49].

Combining the above data with the presence and/or absence of the optical centers in the diamonds of this study, it can be inferred that the irradiation-treated diamonds were irradiated without annealing or the annealing temperature was very low, the minimum annealing temperature was $\sim 2000^{\circ} \mathrm{C}$ for the HPHT-treated diamonds and the annealing temperature for the multiprocess-treated diamond was between 2000 and $2300^{\circ} \mathrm{C}$.

\subsection{Cause of Color}

4.2.1. Blue. In natural diamonds, the blue color is rare. The type IIb diamonds owe their blue color to the absorption of the boron acceptors $[22,50,51]$. Some natural type Ia diamonds can also show the blue-gray color, which is caused by the high concentration of hydrogen $[52,53]$. Moreover, the GR1 center produced by irradiation is another origin of the blue color. A few diamonds are naturally irradiated to display blue color [22], and a similar color can also be induced by artificial irradiation $[28,54]$. The blue diamonds in this study were artificially irradiated, which give rise to strong GR1 center.

4.2.2. Yellow to Green. In natural diamonds, the yellow color is usually caused by the absorption of the N3 and N2 optical centers ("cape-yellow") and/or the C defects (canary-yellow). The green hue of some natural diamonds is due to the GR1 center produced by natural irradiation $[26,54]$. HPHT treatment is a common method to induce yellow/green color to the diamonds. After HPHT annealing at $1800^{\circ} \mathrm{C}$, a yellow hue due to the $\mathrm{C}$ center was created in brown type Ia diamonds $[49,55]$. With increasing temperature, the H2 center-additional green color modifier-was produced $[25,26$, 56]. In general, the resulting green/yellow color is a combination of the absorptions of $\mathrm{H} 3, \mathrm{H} 2$, and $\mathrm{C}$ defect in the spectrum and also the same as the HPHT-treated diamonds in this study. Strong GR1 center created by artificial irradiation can also give rise to dark green color, such as the sample TR-2 and TR-4.

4.2.3. Red. Pure red diamond is extremely rare in nature, and some pink diamonds with moderate brightness and high saturation can display red color [54]. After multiprocess treatment, the diamonds could also show red color. Usually, the type IaAB natural diamonds are chosen to be treated to 
induce the red color $[9,12]$ : firstly, HPHT annealing is performed at over $2150^{\circ} \mathrm{C}$ to achieve high concentration of $\mathrm{C}$ center and then the diamonds are irradiated with $2-4 \mathrm{MeV}$ energy to create enough isolated vacancies; finally, the diamonds are annealing at a temperature exceeding $1100^{\circ} \mathrm{C}$ in order to combine the $\mathrm{C}$ defects with the vacancies into $\mathrm{NV}$ centers; after these, the purple to red color could be obtained. The main reason for the red color is the absorption of $\mathrm{N}-\mathrm{V}$ centers at 575 and $637 \mathrm{~nm}$, with some influence from other absorption features $[15,26,35]$. It is obvious that the red color of the diamonds in this study has been induced by a similar process, because the N-V centers at 575 and $637 \mathrm{~nm}$ were also observed in these multiprocess-treated diamonds.

4.3. Identification Features. Generally, a number of techniques should be combined to identify a certain diamond, as it is difficult to be identified just by means of a single feature [57]. Combination of the presence of internal growth graining and the absence of growth structures typical of HPHT- and CVD-grown diamonds is a common feature of the diamonds in this work, which could confirm that they have grown in nature. Usually, after HPHT treatment, some of the diamonds could display obvious color zoning (especially around the culet or girdle), etched facet near to the girdle which was not repolished, and some graphitized inclusions along fracture surfaces.

The absorption caused by $\mathrm{Hla}$ at $1450 \mathrm{~cm}^{-1}$ in the spectra of FTIR is observed in all the irradiated samples of this study (Figure 4). Besides, the GR1 center related to the isolated neutral vacancies is another common center in irradiated diamonds; however, it easily disappears after high temperature annealing (Figure 5).

Fisher [23] suggested that aggregation of nitrogen in natural diamonds tended to follow a progression: firstly, the single nitrogen aggregates to form pairs, and only after this transformation is completed, the A centers will aggregate further to form B centers. It is rare to find a normal color untreated diamond simultaneously exhibiting strong absorption from both single nitrogen and B centers, and therefore the occurrence of isolated nitrogen associated with the B centers could be considered as a possible indicator of HPHT treatment. It is true that various aggregation states of nitrogen $(\mathrm{C}, \mathrm{A}$, and $\mathrm{B}$ centers) are observed in the FTIR spectra of the HPHT-treated samples in this work. Similarly, the formation of $\mathrm{H} 2$ center requires for the existence of the donors (e.g., the $\mathrm{C}$ center), and therefore the existence of isolated nitrogen together with $\mathrm{H} 3$ and $\mathrm{H} 2$ centers is another possible property related to HPHT treatment $[55,58]$. Although the intensity of the $637 \mathrm{~nm}$ is found to be stronger than that of $575 \mathrm{~nm}$ for the HPHT-treated diamonds in this work, which is considered to be a typical characteristic of HPHT treatment in previous works [4, 49, 59, 60], however, Collins [34] suggested that it is just a rough criterion and works well for approximately $75 \%$ of the HPHT-treated diamonds.

\section{Conclusions}

Recently, the color diamonds have become highly popular and gotten a great value in the jewelry market. Through high-energy irradiation, HPHT treatment, LPHT annealing, and combination of these treatments, many industries and researchers have continuously focused on enhancing the color of diamonds so as to achieve a fancy color. Therefore, the study of these treated-color diamonds appears particularly important for the jewelry testers and customers. In this work, we collected ten treated-color diamonds with different treatment process and characterized them through the most widely used optical gemological and spectroscopic techniques (IR absorption spectrum, PL spectra, and DiamondView). The possible conditions of the treatment and the coloration mechanism of these samples (blue, green, and red) were discussed. It is suggested that the conclusive identification of these treated-color diamonds should be made by a combination of gemological and spectroscopic properties, such as their distinctive growth patterns, color zoning, and absorption features in the IR and PL spectra.

\section{Conflicts of Interest}

The authors declare that there is no conflict of interest regarding the publication of this paper.

\section{Acknowledgments}

This work was financially supported by the National Natural Science Foundation of China (Grant no. 41603064) and China Postdoctoral Science Foundation (Grant no. 2016M591222).

\section{References}

[1] G. E. Harlow, "What is diamond?," in The Nature of Diamond, G. E. Harlow, Ed., Cambridge University Press, Cambridge, 1998.

[2] K. Nassau, Gemstone Enhancement History, Science and State of the Art, Butterworth-Heinemann Ltd, Oxford, 2nd edition, 1994.

[3] A. T. Collins and I. Kiflawi, "The annealing of radiation damage in type Ia diamond," Journal of Physics: Condensed Matter, vol. 21, no. 36, article 364209, 2009.

[4] T. Hainschwang, A. Katrusha, and H. Vollstaedt, "HPHT treatment of different classes of type I brown diamonds," Journal of Gemmology, vol. 29, no. 5-6, pp. 61-73, 2005.

[5] T. Hainschwang, A. Respinger, F. Notari, H. J. Hartmann, and C. Günthard, "A comparison of diamonds irradiated by high fluence neutrons or electrons, before and after annealing," Diamond and Related Materials, vol. 18, no. 10, pp. 12231234, 2009.

[6] M. Hall and T. M. Moses, "Gem trade lab notes: diamond-blue and pink, HPHT annealed," Gems \& Gemology, vol. 36, no. 3, pp. 254-259, 2000.

[7] Y. F. Meng, C. S. Yan, J. Lai et al., "Enhanced optical properties of chemical vapor deposited single crystal diamond by low-pressure/high-temperature annealing," Proceedings of the National Academy of Sciences of the United States of America, vol. 105, no. 46, pp. 17620-17625, 2008.

[8] S. S. Vagarali, S. W. Webb, W. E. Jackson, W. F. Banholzer, T. R. Anthony, and G. R. Kaplan, "High pressure/high 
temperature production of colorless and fancy-colored diamonds," U.S. patent 6692714, 2004.

[9] V. G. Vins, "The technique of production of fancy red diamonds," Russian Federation patent 2237113, 2004.

[10] V. G. Vins, A. P. Yelisseyev, S. S. Lobanov, D. V. Afonin, A. Y. Maksimov, and A. Y. Blinkov, "APHT treatment of brown type Ia natural diamonds: dislocation movement or vacancy cluster destruction?," Diamond and Related Materials, vol. 19, no. 7-9, pp. 829-832, 2010.

[11] V. G. Vins and O. V. Kononov, "A model of HPHT color enhancement mechanism in natural gray diamonds," Diamond and Related Materials, vol. 12, no. 3-7, pp. 542-545, 2003.

[12] V. G. Vins, "Technique of production of fancy red diamonds," US Patent 2007/0053823A1, 2007.

[13] I. M. Reinitz, P. R. Buerki, J. E. Shigley, S. F. McClure, and T. M. Moses, "Identification of HPHT-treated yellow to green diamonds," Gems \& Gemology, vol. 36, no. 2, pp. 128-137, 2000.

[14] J. E. Shigley, "High-pressure-high-temperature treatment of gem diamonds," Elements, vol. 1, no. 2, pp. 101-104, 2005.

[15] W. Wang, C. P. Smith, M. S. Hall, C. M. Breeding, and T. M. Moses, "Treated-color pink-to-red diamonds from Lucent Diamonds Inc," Gems \& Gemology, vol. 41, no. 1, pp. 6-19, 2005.

[16] C. M. Welbourn, M. Cooper, and P. M. Spear, "De beers natural versus synthetic diamond verification instruments," Gems \& Gemology, vol. 32, no. 3, pp. 156-169, 1996.

[17] S. Liggins, M. E. Newton, J. P. Goss, P. R. Briddon, and D. Fisher, "Identification of the dinitrogen $<001>$ split interstitial H1a in diamond," Physical Review B, vol. 81, no. 8, article 0852145, 2010.

[18] C. D. Clark, R. W. Ditchburn, and H. B. Dyer, "Absorption spectra of natural and irradiated diamonds," Proceedings of the Royal Society A: Mathematical, Physical and Engineering Sciences, vol. 234, no. 1198, pp. 363-381, 1956.

[19] G. S. Woods, "Platelets and the infrared absorption of type Ia diamonds," Proceedings of the Royal Society A: Mathematical, Physical and Engineering Sciences, vol. 407, no. 1832, pp. 219-238, 1986.

[20] F. S. Gentile, S. Salustro, M. Causa, A. Erba, P. Carbonniere, and R. Dovesi, "The VN3H defect in diamond: a quantummechanical characterization," Physical Chemistry Chemical Physics, vol. 19, no. 33, pp. 22221-22229, 2017.

[21] A. Mainwood, "Nitrogen and nitrogen-vacancy complexes and their formation in diamond," Physical Review B, vol. 49, no. 12, pp. 7934-7940, 1994.

[22] A. M. Zaitsev, Optical Properties of Diamond: A Data Handbook, Springer-Verlag, Berlin, 2001.

[23] D. Fisher, "Brown diamonds and high pressure high temperature treatment," Lithos, vol. 112, pp. 619-624, 2009.

[24] W. Wang, P. Doering, J. L. R. Tower et al., "Strongly colored pink CVD lab-grown diamonds," Gems \& Gemology, vol. 46, no. 1, pp. 4-17, 2010.

[25] L. Tretiakova, "Spectroscopic methods for the identification of natural yellow gem-quality diamonds," European Journal of Mineralogy, vol. 21, no. 1, pp. 43-50, 2009.

[26] I. A. Dobrinets, V. G. Vins, and A. M. Zaitsev, HPHT-Treated Diamonds, Springer Series in Material Science, Berlin, 2013.

[27] J. E. Shigley, E. Fritsch, J. I. Koivula, N. V. Sobolev, I. Y. Malinovsky, and Y. N. Pal'yanov, "The gemological properties of Russian gem-quality synthetic yellow diamonds," Gems \& Gemology, vol. 29, no. 4, pp. 228-248, 1993.
[28] A. T. Collins, "Optical centres produced in diamond by radiation damage," New Diamond and Frontier Carbon Technology, vol. 17, no. 2, p. 47, 2007.

[29] A. T. Collins, A. Connor, C. Ly, A. Shareef, and P. M. Spear, "High-temperature annealing of optical centers in type-I diamond," Journal of Applied Physics, vol. 97, no. 8, article 083517, 2005.

[30] V. G. Vins and A. P. Yelisseyev, "Effect of high pressure, high temperature annealing on impurity-defect structure of natural diamonds," Perspectives Materials, vol. 1, pp. 49-57, 2010, (in Russian).

[31] E. J. Brookes, A. T. Collins, and G. S. Woods, "Cathodoluminescence at indentations in diamonds," Journal of Hazardous Materials, vol. 4, pp. 98-105, 1993.

[32] F. De Weerdt, R. Galloway, and A. Anthonis, "Defect aggregation and dissociation in brown type-Ia diamonds by annealing at high pressure and high temperature (HPHT)," In Defect and Diffusion Forum, vol. 226, pp. 49-60, 2004.

[33] A. T. Collins, "Colour centers in diamond," Journal of Gemmology, vol. 18, no. 1, pp. 37-75, 1982.

[34] A. T. Collins, "The detection of colour-enhanced and synthetic gem diamonds by optical spectroscopy," Diamond and Related Materials, vol. 12, no. 10-11, pp. 1976-1983, 2003.

[35] A. T. Collins, H. Kanda, and H. Kitawaki, "Colour changes produced in natural brown diamonds by high-pressure, high-temperature treatment," Diamond and Related Materials, vol. 9, no. 2, pp. 113-122, 2000.

[36] F. De Weerdt and J. Van Royen, "Defects in coloured natural diamonds," Diamond and Related Materials, vol. 10, no. 3-7, pp. 474-479, 2001.

[37] A. T. Collins, "Investigating artificially colored diamond," Nature, vol. 273, no. 5664, pp. 654-655, 1978.

[38] V. G. Vins and A. P. Eliseev, "Effect of annealing at high pressures and temperatures on the defect-admixture structure of natural diamonds," Inorganic Materials: Applied Research, vol. 1, no. 4, pp. 303-310, 2010.

[39] V. G. Vins and A. P. Yelisseyev, "Physical fundamentals behind modern techniques of natural diamond enhancement," Australian Gemmologist, vol. 24, pp. 219-221, 2008.

[40] V. G. Vins, A. P. Yelisseyev, and V. Sarin, "Physics behind the modern methods of enhancement of natural diamonds," Precision Metals Precision Stones, vol. 12, no. 180, pp. 155-163, 2008.

[41] D. Fisher, D. J. F. Evans, C. Glover, C. J. Kelly, M. J. Sheehy, and G. C. Summerton, "The vacancy as a probe of the strain in type IIa diamonds," Diamond and Related Materials, vol. 15, no. 10, pp. 1636-1642, 2006.

[42] H. Lim, S. Park, H. Cheong, H. M. Choi, and Y. C. Kim, "Discrimination between natural and HPHT-treated type IIa diamonds using photoluminescence spectroscopy," Diamond and Related Materials, vol. 19, no. 10, pp. 1254-1258, 2010.

[43] I. Kiflawi, A. T. Collins, K. Iakoubovskii, and D. Fisher, "Electron irradiation and the formation of vacancy-interstitial pairs in diamond," Journal of Physics: Condensed Matter, vol. 19, no. 4, article 046216, 2007.

[44] G. Davies, "Charge states of the vacancy in diamond," Nature, vol. 269 , no. 5628, pp. 498-500, 1977.

[45] F. De Weerdt and A. T. Collins, "HPHT annealing of natural diamond," New Diamond and Frontier Carbon Technology, vol. 17, no. 2, 2007. 
[46] J. P. Goss, P. R. Briddon, V. Hill, R. Jones, and M. J. Rayson, "Identification of the structure of the $3107 \mathrm{~cm}^{-1}$ H-related defect in diamond," Journal of Physics: Condensed Matter, vol. 26, no. 14, article 145801, 2014.

[47] V. G. Vins, "Changing diamond colour," Best Gemology, vol. 1, no. 3, pp. 19-30, 2001.

[48] F. De Weerdt and I. N. Kupriyanov, "Report on the influence of HPHT annealing on the $3107 \mathrm{~cm}^{-1}$ hydrogen related absorption peak in natural type Ia diamonds," Diamond and Related Materials, vol. 11, no. 3-6, pp. 714-715, 2002.

[49] A. T. Collins, "Colour of diamond and how it may be changed," Journal of Gemmology, vol. 27, no. 6, pp. 341-359, 2001.

[50] A. T. Collins and P. M. Spear, "Optically active nickel in synthetic diamond," Journal of Physics D: Applied Physics, vol. 15, no. 12, pp. L183-L187, 1982.

[51] S. C. Lawson, H. Kanda, and M. Sekita, "New nickel-related optical absorption in high-pressure synthetic diamond," Philosophical Magazine B, vol. 68, no. 1, pp. 39-46, 1993.

[52] J. Darley and J. M. King, "Natural color hydrogen-rich blue-gray diamond," Gems \& Gemology, vol. 43, no. 2, pp. 155156, 2007.

[53] E. Fritsch and K. Scarratt, "Natural-color nonconductive gray-to-blue diamonds," Gems \& Gemology, vol. 28, no. 1, pp. 35-42, 1992.

[54] H. Kitawaki, "Gem diamonds: causes of colors," New Diamond and Frontier Carbon Technology, vol. 17, no. 3, pp. 119-126, 2007.

[55] Y. C. Kim and H. M. Choi, "A study on the HPHT-processed NOUV diamonds by means of their gemological and spectroscopic properties," Journal of the Korean Crystal Growth and Crystal Technology, vol. 15, no. 3, pp. 114-119, 2005.

[56] W. Wang and M. Hall, "HPHT-treated type Ia diamond with a green component caused by the $\mathrm{H}_{2}$ defect," Gems \& Gemology, vol. 43, no. 2, pp. 156-158, 2007.

[57] M. E. Newton, "Treated diamond: a physicist's perspective," Gems \& Gemology, vol. 42, no. 3, pp. 84-85, 2006.

[58] F. De Weerdt and J. Van Royen, "Investigation of seven diamonds, HPHT treated by NovaDiamond," Journal of Gemmology, vol. 27, no. 4, pp. 201-208, 2000.

[59] J. P. Chalain, E. Fritsch, and H. A. Haenni, "Diamants de type IIa et traitement HPHT: Identificatio," Revue de Gemmologie, vol. 141, pp. 50-53, 2001.

[60] L. Tretiakova and Y. Tretyakova, "In significance of spectroscopic methods for the identification defects in diamond," in 9th International Kimberlite Conference, Extended Abstract No. 9IKC-A-00042, 2008. 

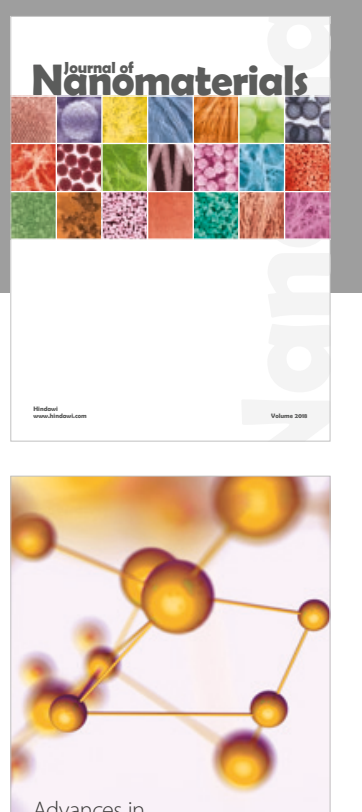

Physical Chemistry
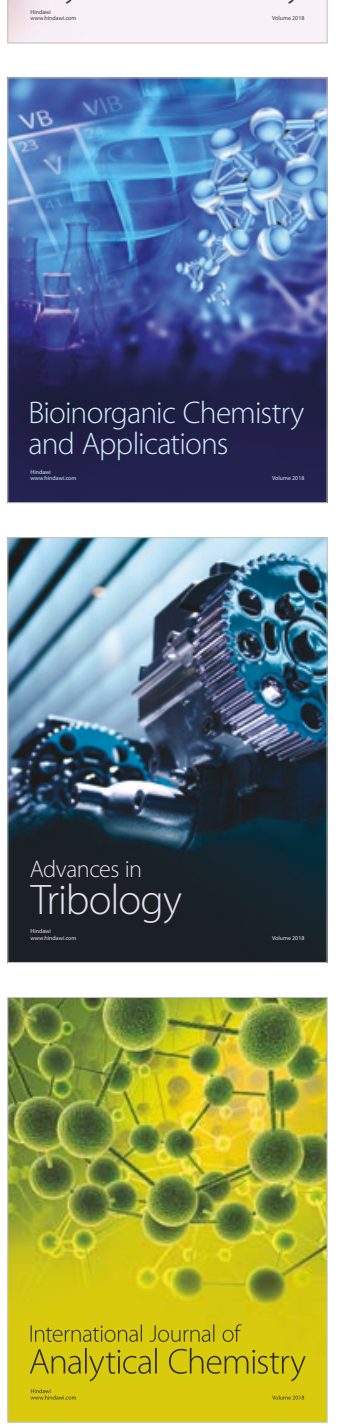

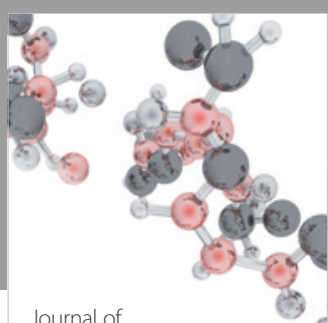

Analytical Methods

in Chemistry

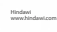

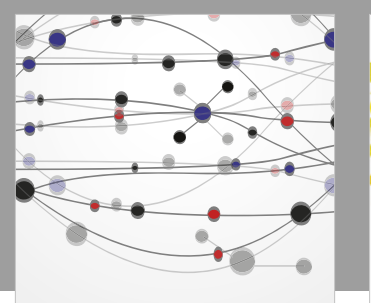

The Scientific World Journal

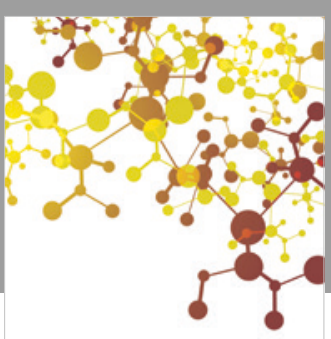

Journal of

Applied Chemistry
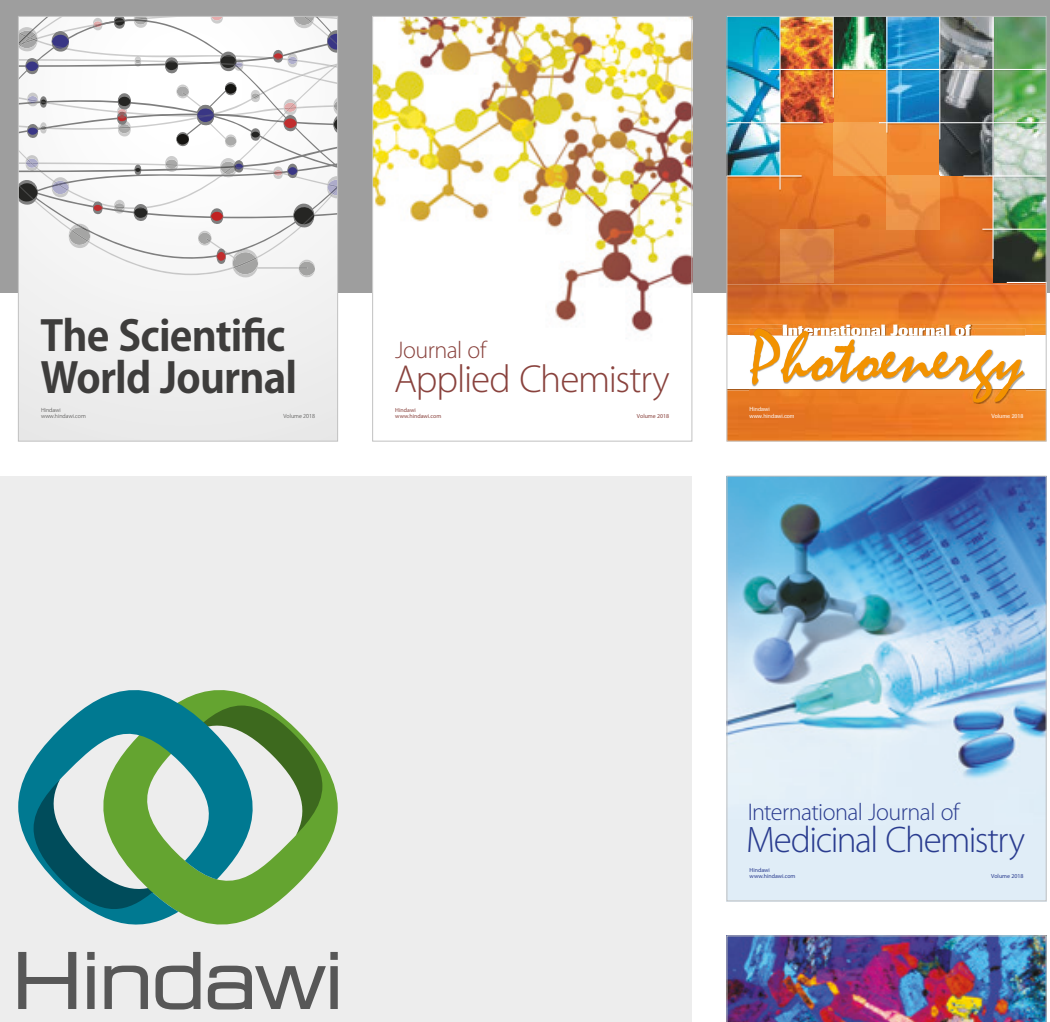

Submit your manuscripts at

www.hindawi.com
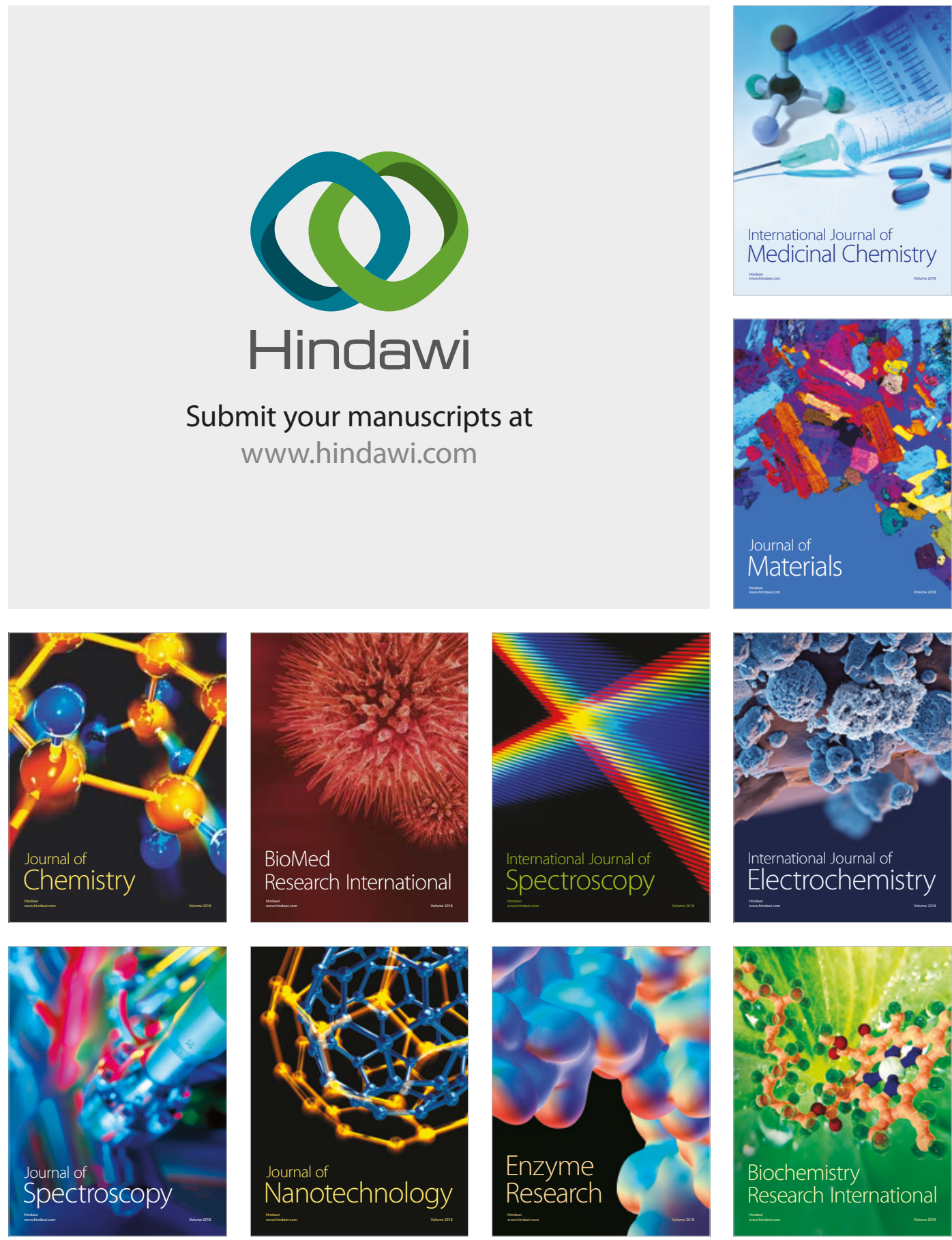
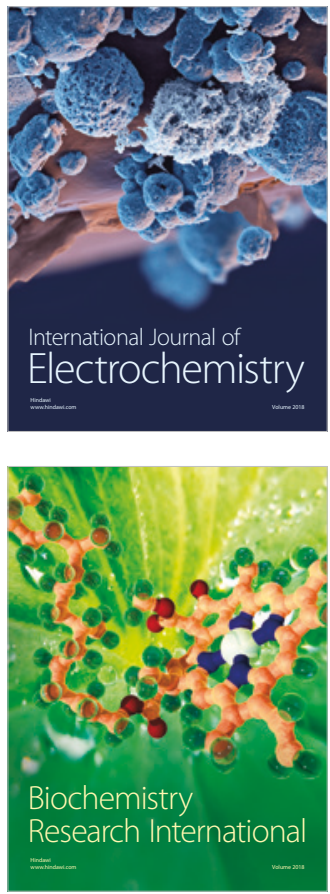